\title{
Mobile Phone: Calling and Texting Patterns of College Students
}

\section{in Pakistan}

\author{
Sohail Kamran \\ Department of Business Administration, Fatima Jinnah Women University \\ Rawalpindi, Pakistan \\ E-mail: sohkam@hotmail.com
}

\begin{abstract}
This paper qualitatively investigated the mobile phone calling and texting patterns among youth in Pakistan. Initially, the data was gathered from seventy seven $(n=77)$ college students aged 17-21 years, who completed twenty four hours mobile phone communication diaries. Completed communication diaries were followed by twenty three in-depth interviews with the college students to collect detailed background information. Study results revealed congruity of SMS and calling patterns among male and female youth. This research discovered that the majority of youth is extremely high user, fond of texting and low user of voice calls. This research unfolded that the youth do most of the mobile phones communications within their age group, communicate in both positive and negative ways. However, majority of mobile phone communications among youth could be categorized as problematic with reference to the place, time, and purpose. The main motivation of high and problematic use among youth is very low priced prepaid packages offered by the telecom operators in Pakistan. Policy implications for the regulatory body are to educate the youth about the appropriate and inappropriate use of mobile phone technology, and issuance of code of advertising to the telecom operators in Pakistan.
\end{abstract}

Keywords: Youth calling behavior, Youth texting behavior, Mobile phone consumption

\section{Introduction and Theoretical Background}

Growing benefits of mobile phones are undeniable and many Studies highlighted advantages of mobile phone use, such as young people form and support relationships with others (Power and Horstmanshof, 2004), widening social networks due to ease of contact (Srivastava, 2005), sense of security and safety among the of mobile phone users as users can contact others in case of emergency (Taylor and Harper, 2001,Chapman and Schofield, 1998, Carroll et al. 2002), social gratification of youths from mobility, access and convenience (Tjong et al, 2003), busy working parents are better able to communicate with their children (Frissen, 2000 and Matthews, 2004), redirecting trips that have already started, softening and changing of schedules, and progressive refinement of an activity, such as filling in details of open-ended plans through mobile phones communication. Even deaf people can better communicate with each other through SMS (Power and Power, 2004). These uses of the mobile phone have changed the patterns of coordination in many areas of our social life, including peer groups, families, and work (Ling and Yttri 2002). In short, people of all ages have benefited from the mobile phone consumptions in the modern societies.

But, researches have also identified potentially problematic and excessive use of mobile phones among teenage and youth segments (Bianchi and Phillips 2005, Paragras, 2003, Monk et al 2004, Palen et al 2001). A study conducted by James and Drennan (2005) in Brisbane, Australia revealed that usage rate among the students were high ranging from 1.5 Hours to 5 Hours per day, and an average bill per month were \$140, which is very expensive given the low student income. However, another study by Matthews (2004) found that Australian adolescents are the low users of the mobile phones, with $97 \%$ of teenagers mobile phone users making fewer than five calls per day and 85\% using SMS fewer than five times per day (Matthews, 2004).

Work of Ling (2005) shows linkage between adolescent criminality and mobile telephone use. Heavy users of mobile telephone are over represented among those who are involved in various forms of deviance such as, fighting, alcohol and narcotics use, various forms of theft, etc (Ling 2005). School, College and University students use mobiles during their classes (Srivastava, 2005). Youth often use mobile phone while driving, which is a considerable safety risk (McEvoy et al. 2005). Therefore, it is vital to understand the calling and texting patterns of the youth and issues linked with their consumption in the contemporary societies. Youth often use their mobiles in different banned settings such as hospitals, planes, petrol stations, and while driving, (Bianchi 
and Phillips, 2005, Palen et al, 2008), mobile conversations in different other public spaces (Paragras, 2003), excessive and problematic use (Bianchi and Phillips 2005).

Japanese youth sends brief text messages to each other in places where it would have been inappropriate, or private enough, to have a conversation before. Students often share text messages with each others during their classes and also use mobile in front of their parents. So the mobile phones give the ability to youth to exchange silent messages anytime, anywhere, respond to each other quickly, and creating the feelings of always being connected (Warner 2003).

According to a study conducted by James and Drennan (2005) one of the major negative consequences of addictive mobile phone use is financial cost or really expensive mobile phone bills. Apart from the significant financial issues, study uncovered a wide range of negative consequences for addictive mobile phone consumers such as damaged relationships, emotional stress and falling literacy (James and Drennan 2005). According to Griffiths and Renwick (2003) Young mobile phone consumers experience great level of phone bills debt, which leads to the financial worries for some young adults (Griffiths and Renwick 2003).

Aoki \& Downes (2003) examined mobile phone consumption among college students in USA, through focus groups and survey studies. Most of the study participants bought mobile phone, when they started their college. Majority of the respondents made five or fewer calls per day, most of the calls were made from on the street followed by at home and at school. Students used most often their cell phones to call friends and relatives, boyfriends or girlfriends, and immediate family members. Majority of the respondents made calls at night. More than half of the respondents' mobile phone bills were paid by their parents (Aoki \& Downes 2003).

Although, all schools formally restrict mobile phones in the classrooms, but most students do use email during classes occasionally. It is common for students to bring their mobile phones in the classes, claiming that they use only clock function. Although, students do not use voice communication during classes, but they read and sometimes send messages during classes. Students use mobile phone most frequently during the lunch time hour and immediately after school, as pupils desperately want to get in touch to their friends (Ito, 2006). Using mobile phones may also help young people gain and maintain peer group acceptance (Cova 1994) proposed that to satisfy their desire for communities, youth seek products less for their own use value than for their linking value.

Several researchers have started to explore issues of mobile phone consumption, identity and general societal impact. Their work often highlighted negative and positive aspects of mobile phone use. Peer-to-peer mobile communications may include acts of malice and intimidation (Haste 2005). There is, however, relatively little research evidence concerning the extent to which more problematic aspects of mobile phone use match young people's everyday experiences (Mort \& Drennan 2004).

Mobile phone is rapidly becoming an important feature of our culture and lives, yet we do not understand its effects on communicative practices and behavior, particularly with reference to the communication and co-evolution of the technology and individual's activity. As use of mobile telephony grows in the contemporary societies, empirical understanding of practice and social impacts becomes relevant for scholars and practitioners alike (Palen et al 2008). Studies related of mobile telephony consumption are few (Palen et al, 2008), especially research into the problematic areas of mobile phones consumption are hindered by a lack of good quality data (Australian Government, 2005, p. 32).

\subsection{Information about the Pakistan's Telecom sector and Objectives of the Study}

Pakistan has emerged as one of the fastest growing mobile markets among the developing nations. In September, 2009 cellular mobile services were available in 7011 cities, towns and villages with network coverage of almost $90 \%$ of the total population. According to a report issued in September, 2009 total subscribers have reached 90.3 million, which is $58 \%$ of the total population. However, the trend in subscriptions remained tilted towards prepaid subscriptions with $98 \%$ prepaid and only $2 \%$ postpaid subscriptions (Mehran 2009).

At present, five Cellular Mobile Telecom Operators (CMTOs) are working in Pakistan. Intense competition among these telecom companies has led to drastic reduction in the tariffs thereby bringing it within the purchasing power of the common man, thus enabling him to acquire this much desired facility (Qizilbash 2007).

Likewise other contemporary societies, youth in Pakistan has also rapidly adopted the mobile phone technology. The adolescent and youth are recognized as one of the largest, attractive and most productive users of mobile phone technology. Although, the most updated figures are not available, but in 2004 young people aged 15-24 were estimated 36 millions which is about $22 \%$ of the total Pakistani population (Sultana 2006). 
Most of the telecom operators' prepaid packages are targeted to youth, because of their heavy mobile phone use. However, there is no research in the Pakistani context regarding the calling and texting behavior of youth. Thus, this study intends to meet the following objectives.

(i) To explore the texting and calling behavior of the college students

(ii) To investigate and analyze the problematic consumption behaviors among college students.

\section{Methodology}

The present exploratory study took place in Rawalpindi, Pakistan by using qualitative research approach. The data generated could afterward be tested by applying any quantitative approach by using a larger sample size. To accomplish study objectives multi-method approach was used. So, the primary data for the current study comes from the following two sources.

\subsection{Hours Mobile Phone Communication Diaries}

To know the calling and texting behaviors of youth initially, college students were asked to keep 24 hours mobile phone communication diaries. Permission was taken from the respective college principals to approach the college students for completing 24 hour mobile phone communication diary. All the participants volunteered to complete the communication diaries. Communication diaries were completed by students of four different colleges' students. These colleges are located predominantly around the working middle class residential areas of Rawalpindi. So the study participants primarily represented middle social class youth of the society.

The population age group was ranged from 17-21 years. A total of 113 diaries, fairly evenly balanced between genders were distributed to college students for completion. However, only seventy seven ( $\mathrm{n}=77$ ) completed diaries were received from the respondents. Forty two $(42,55 \%)$ male students and thirty five $(35,45 \%)$ female college students gave the completed diaries back.

A critical qualifying criterion to select the study participants was that they own and use mobile phones. These diaries were fairly structured, where most of the activities were pre- categorized. A short diary was designed to be filled by the respondents. First page of the diary contained the instructions on how to complete the communication diary. As most part of the day diary was linked to the time-use data of mobile phone and according to Corti (1993) for gathering time use data one to three days diaries may be used (Corti, 1993). Students were asked to record all the received and made calls and text messages during 24 hours, time of each call and text message, duration of each call, number of received and made calls and text messages, average monthly expenses incurred, place of calling and texting, purpose or reason, and the person contacted. Completed mobile phone communication day diary results were shown in the tables as a whole.

\subsection{In-depth Interviews}

The day diaries were followed by the in-depth interviews to explore the details about the diary entries. This method is considered as one of the reliable methods of obtaining information (Corti, 1993). In total, Twenty three In-depth interviews were conducted with college students to gather more background information regarding the general texting and calling patterns, and to explore about the problematic use of mobile phone among youth. These in-depth interviews were conducted between October 212009 and November 25, 2009. The gender divide was roughly equal and eleven female students and twelve male students participated in the in-depth interviews. From each college selected students were interviewed about their diaries in their college premises in a separate quiet room with permission of respective college principal. To maintain the uniformity and consistency all the interviews were carried out by the author. An interview guide was prepared and for the purpose of getting more details on the study topic probing questions were asked from the interviewees. All the interviews were audio recorded with the permission of interviewees and confidentiality was assured. For the purpose of interview data analysis content analysis approach was used.

\section{Results}

The study results show that most of the students are low users of voice calls both in terms of receiving and making calls. There are similarities in calling and texting communication patterns of both male and female students.

Table one shows that Nine participants (11.68\%) did not receive any call and fourteen $(18.18 \%)$ did not make any call on the diary day. Thirty five students (45\%) received calls of only 1-15 minutes and twenty four (31\%) dialed calls of only 1-15 minutes. Nine respondents (11.68\%) received and fourteen respondents dialed calls of 31-45 minutes, which is a moderate use of voice calls. Only four study participants $(5.20 \%)$ received and dialed 
calls of 46-60 minutes. Only Seven participants (9\%) received and six participants (7.8\%) made calls of more than an hour (Please see Aappendix-1).

Table two shows that forty two participants (54\%) received and thirty seven students (48\%) dialed 1-4 calls. Fifteen students (19\%) received and twelve participants $(15.6 \%)$ dialed 5-8 calls on the diary day. Only four participants $(5 \%)$ received and seven $(9 \%)$ dialed calls in the range of $9-12$. Total seven participants $(9 \%)$ received and dialed either 13 or more calls on the diary day (Please see Aappendix-1).

Table three shows that average received calls by male students were 4.3 and per female students were 4.1 on the diary day. Average number of dialed calls by the male students remained 3.9 and by female students 3.4 . This suggests a low use of mobile phone voice calls among the majority of participants. However, students reprted an incredibly high rate of SMS communications on the diary day. Average number of SMS received by a male student remained 98.4 and by a female 85.7. Similarly average number of text messages sent remained almost same among male and female. Male students sent 109.5 and female students sent 98.2 text messages on the diary day (Please see Appendix-1).

Study results show that most of the study participants are low users of mobile phone voice calls both in terms of outward and inward calls. Some of the Interviewed students, who did not make and receive any call on the diary day or who reported very less number of received and dialed calls, stated that they do not prefer to communicate through voice calls very often with their friends and family members and whenever they have to communicate they prefer to communicate through SMS. Secondly, some students did not have the credit in their mobile phones and others have bought the SMS bundle packages offered by the cellular companies. These respondents also told that they seldom use their home land line to ring to their teachers, friends and relative. Some low users stated that they only use mobile phone calls when it is extremely important. It is also interested to note that few students reported that they give missed call to their friends; family members and, relatives etc and then they call back or reply by text message.

Here are some excerpts from a group of college students interviewed.

Interviewer: Why you did not make any calls in whole diary day?

Student 1: I had Zero credit. Actually, it is more expensive to buy both SMS and voice minutes bundle packages... I only buy the SMS monthly bundle package which is very cheap and I can communicate easily.

Interviewer: what were the reasons that you even did not receive any call on your mobile phone?

Student 2: When I go to the school I switch off my mobile phone and my friends mostly communicate with me through SMS.

Interviewer: Who else calls you other than your friends and why?

Student 2: My parents some times ring me when I am away from my home to ask my location and... my relatives ring me. Other than that some time any class fellow makes a very short conversation over the phone with me.

Interviewer: What is the reason of very low mobile phone calls made by you?

Student 3: I just make very important calls and like texting.

Interviewer: What are those important calls?

Student3: In case of any emergency, calling to my teachers some time for asking any question and sometimes to my parents, and relatives.

A few respondents were moderate and few were high users of voice calls. The primary purpose for calling told by both moderate and high users during the interview was to call friends, and sometimes class fellows and family members. Students from both genders use mobile phones in different banned settings for their voice calls. Some students reported that they take the calls while they ride their motorbike, drive cars, on the petrol station, in the library, computer lab, sitting in the gathering of others etc. However, students avoid making the calls from different banned setting such as class rooms and places mentioned above. Most of the communications both inward and outward were done by the students with their own age group, friends and class fellows. Most of the moderate and high mobile phone users stated that the reasons of long calls are mostly love or friendship, sharing information and passing time. Most of the long duration calls are mostly made to the friends or class fellows. However, majority of the mobile phone short communications are done to share information with parents, teachers, class fellows and friends.

A passage of the interview of a female moderate user who called more than 31 minutes on the diary day said: 
Interviewer: To whom you make the calls and who calls you, both long and short calls?

Student: My long calls are mostly to my friends...my short calls to parents for telling or asking anything. My friend mostly calls me and some short calls are received from my parents and family members.

Interviewer: What are those places where you mostly make and receive calls?

Student: I mostly make calls from my own room or while in the home and some times in the college cafeteria. I try not to miss the call ....even... sitting in the library, traveling or in the Bazar or busy in any other activity, because I have to ring back and it cost me my free minutes.

Few interviewed high users of voice calls bought free hours packages. Those free hours were mostly used to ring to very close friends of similar or opposite sex. Students also reported that their parents sometimes stop them from high mobile phone use, especially in night time. High users also reported that sometimes they cannot get up early morning because they were talking with their friends till late night. So sometimes either they miss their class or go to their college late. One of the passages of the interview conducted with a male college student is given below.

Interviewer: To whom you make the long calls and who makes you mostly the long calls?

Student: To my girl friend and ... my girl friend and a friend rings me

Interviewer: What time do you make and receive these calls?

Student: Mostly night and late night... while I $\mathrm{m}$ in my bed.

Interviewer: How often you ring to your friend in late night?

Student: About 3 to 4 times in a week.

Interviewer: Do your parents know that you communicate with your friend late night over the mobile phone?

Student: Yes they do know.

Interviewer: So what do they say you?

Student: ... they tell me off very often, but then when my friend rings me or some times give me missed call then I have to call her back. My mother says me softly, but my farther sometimes scolds me over the night time mobile phone use.

Interviewer: What are the negative consequences on your studies and health of you late night and heavy mobile phone use?

Student: If I talk till late night... I feel tired ...sometimes I miss the class because I cannot get up early in the morning.

Table four shows that voice calls have been received and made during the whole 24 hours by the college students. But a very low usage rate was reported by the students in the morning times (6:01AM-12:00PM) and only $6.2 \%$ of total calls were received and $4.7 \%$ total calls were made by the students in this time. $19.3 \%$ total calls were received and $17 \%$ total calls were dialed in the afternoon (12:01 to 18:00 PM). Most of the calls were made by the students in evening and late evening (18:01PM to 00:00AM) and 39.50\% of total calls received and $45.20 \%$ of total calls were dialed during this time. About one third of the total calls received and dialed were made during late night and early morning (00:01 AM to 6:00 AM), and 35\% of the total calls were received and 33\% were dialed during late night and early morning.

Likewise voice calls text messages have been sent and received by the students in different times of the day and night. About 23.3\% received and 20.4\% of total messages were sent in the morning times (6:01AM-12:00PM). $21.5 \%$ total SMS were received and $24.20 \%$ of total SMS were sent in the afternoon (12:01 to 18:00 PM). Like the voice calls most of the text messages were received and made by the students in evening and late evening (18:01PM to 00:00AM) and 48\% of total messages were received and 50.8\%of total SMS were sent during this time. Unlike heavy use of voice call minutes by the students only in the late night and early morning $7.2 \%$ of the total received and $4.6 \%$ of the total made text messages were recorded during late night and early morning times(00:01 AM to 6:00 AM) (Please see Appendix-1).

College students of both genders are fond of sending and receiving large number of text messages. Table five shows that on the diary day only three participants (3.90\%) did not receive and two participants $(2.60 \%)$ did not sent any SMS. Nine students received (11.70\%) and seven students $(9.10 \%)$ sent 1-25 messages on the diary day. Eleven students $(14.30 \%)$ received and eight students $(10.38 \%)$ sent 26-50 SMS on the diary day. Eleven students about (14.30\%) received and sent 51-75 text messages. Eight study participants (10.37\%) received and 
seven (9.10\%) sent 76-100 messages from their mobile phone on the diary day. Thirty five (45.44\%) of the study participants received and forty two (54.54\%) sent more than 100 text messages on the diary day (Please see Appendix-1).

This explains an extremely high text messaging by the youth. The main reasons told by almost all the interviewed students was the low tariff rates of the texting, easy communication even sitting in crowd, class room or in the library etc. Students communicate through the text messages on all the places like college, library, college computer lab, sitting in public gathering or with parents, market place, traveling on public transport and walking on the road etc. Almost all the students said that majority of SMS communications take place with the friends, class fellows and boy or girl friend. Occasionally SMS are sent and received from parents and siblings as well. Interviewed students reported that the purpose of text messages or kind of SMS communications are mostly funny, sharing information, love, and friendship. Some times they sent the greeting, religious and insulting, teasing and dirty jokes SMS to their friends. Some interviewees reported that their parents some time stop them to carry the mobile and send messages, while eating or studying etc. Here is an extracts from an interview.

Interviewer: What are the reasons of such a heavy SMS usage?

Student: It is very cheap and we can talk with our friends whole day without any hassle.

Interviewer: What are those places from where you communicate through SMS?

Student: Sir... not restricted to the place, any place, anytime for example, class room, library, on the road, on the bus and in the home.

Interviewer: How you manage to send and receive text messages from class room?

Student: We put the mobile on silent and keep communicating because it does not ring.

Interviewer: What do your teachers say about the class room mobile phone usage?

Student: Sir... few teachers are very strict and in their class we do not use a lot but others are somewhat lenient... we send a lot of text communication in their classes.

Interviewer: What happens if you are caught using your mobile phone in the class?

Student: Sometime they confiscate our mobile phone and give it to administration and then we pay fine but mostly we make excuse that we were watching time or doing nothing with mobile.

Interviewer: What type of SMS messages you sent and receive?

Student: We share messages for sharing information, funny, sexy, dirty, love messages, greeting and religious messages with each other.

All most all the students were discussed about the inappropriate mobile phone communications with reference to the place, time and purpose. It was shocking to know that except the use of mobile phones in the class room, student do not perceive any other inappropriate use of mobile phone with reference to the place, time and purpose. Here is an excerpt of an interview conducted with a female college student.

Interviewer: In your view, what are the inappropriate uses of mobile phones?

Student: I do not think any... if used in the class room...nothing else...

Interviewer: What do you think about late night long calls and communications while driving, in computer labs and library etc?

Student: I do not think it is a problem....as every one uses

Table six shows the mobile phone monthly expenses incurred by the different students. It clearly indicates that per month expenses remain very low and only eleven (14\%) students reported spending of 501 to 750 Pakistani rupees per month. Majority, as table shows did spend very less or moderate amount on buying the voice minutes and text message packages (Please see Appendix-1).

Almost all the students interviewed admitted that the monthly expenses made on the mobile phones are not a real financial burden for us. An excerpt from an interview with a male college student is given below.

Interviewer: What are the main reasons of making a lot of text messages and calls?

Student: ...packages are offered on very low rates...I have a lot of friends as well... 


\section{Analysis and Discussion}

The cellular services have been widely adopted by the urban Pakistani youth. Mobile phone has brought communication ease and benefits for all spheres of life and especially for the youth. This study found similar mobile phone communication patterns among both male and female. Students mostly communicate with their own age group such as friends and class fellows etc. The convenience of communication definitely provides an opportunity to the youth to improve their social network as also mentioned in the literature by Srivastava, (2005) and Power and Horstmanshof, (2004), sense of security as mobile phone users can contact others in case of emergency (Taylor and Harper, 2001, Chapman and Schofield, 1998, Carroll et al. 2002), social gratification of youths from mobility, access and convenience (Tjong et al, 2003).

But, on the same time the SMS and calling among youth has raised some issues in the modern societies. Present study found that a significant number of the students are the low users of the voice calls. So our study results are similar to the results of the study conducted in Australia by Mathews (2004), where most of the adolescents made lesser than five calls per day. But, according to our study results, it is noticeable that high users of the mobile phones communicate mostly in night or late night. As most of the adolescent and youth group goes to the schools or colleges, so the time of mobile phone use makes it problematic. Potentially, those users who do long conversations in late night would feel lazy and tired to go to the college and occasionally leave the class as well. According to the findings of James and Drennan (2005) one of the consequences for addictive mobile phone consumers is falling literacy (James and Drennan 2005). As the students can not take a proper sleep in the night as they remain busy talking on their mobiles, so it might be difficult for them to attend the lecture attentively and understand the lesson. Mobile phones excessive and late night use among the teenage sometimes becomes the source of conflict with their parents. The main reasons of this conflict are that the parental telephone communication norms with reference to the time, place and purpose were mostly different than their offspring. So, there is a perception gap between the parents and children about the appropriate and inappropriate use of mobile phone technology. Secondly, communication on mobile phones sometimes defies the parental and cultural values. For example; before the emergence of mobile phone technology, it was uncommon among Pakistani youth to communicate with opposite gender over the phone for long duration and in the presence of others. Thirdly, parents also feel that excessive and late night use of the mobile phone may negatively affect the studies of their children.

Although, none of the students made or received voice calls from their class room, but most of them reported frequent communication in different banned settings such as petrol station, computer labs, library etc. Our study results do have the similarities of what is reported by the different other researchers like Bianchi and Phillips (2005) and Palen (2008). Although, it has been documented by the Bianchi and Phillips (2005) and Palen (2008) and McEvoy et al. (2005) that teen use mobile phones while driving, which is considered very risky, but the present study also found out that students do mobile phone conversations while driving and riding bikes. Although, mobile phone conversation while driving is dangerous as the driver can not pay full attention, but using mobile during riding motorbike are extremely dangerous activity and a real safety hazard.

Our study results show an incredibly high SMS communications among the Pakistani youth. Likewise the mobile phone voice calls, SMS communications are carried out in almost all the places, at all times and for all purposes. Majority of these SMS communications could be classified as problematic. Especially, students do also send and receive text messages in their class rooms or during their lectures. This definitely have a very negative impact on the learning abilities of the students, as they can not concentrate fully on their lecture. Secondly, one student sending or reading text messages potentially involve others in the activity as other students' attention is also diverted. Thirdly, mobile phone use by one student in the class room probably tempts and sometimes encourages other pupils to use mobile phone during the class room, as majority of teens like to fit in to their peer group by doing the same type of activities. So mobile phone use during classes not only decreases the learning prospects for the individual user, but probably for most of his class mates as well. Our study have similar findings as previously reported by the Warner (2003) and Srivastava (2005), which revealed that students often send and receive text messages during their classes. Present study results revealed that students do SMS communications from their college computer labs and library, while driving and even sitting in the company of others. The purpose of these SMS communications may be appropriate but the place of communications makes it inappropriate.

Although, students use SMS communications for the positive purposes such as, sharing information and greeting etc. However, it is also noticeable that the purpose of most of SMS sent and received is not positive. For example: most of the text messages are funny and even dirty, insulting for a specific group of people, teasing others and even sometimes spreading the rumors. This is surely not a positive use of SMS technology. 
The youth remains a highly price sensitive segment, but SMS bundle packages and voice minutes packages targeted to the youth are offered on incredible lower rates. For example, almost all the telecom companies in Pakistan offer 1000SMS bundle packages on 08-11 Pakistani Rupees per week and per day unlimited text message packages on 2-3 Pakistani Rupees. Similarly night voice calls minutes packages are offered as low as 4-6 Pakistani Rupee per hour. This is the major stimulus for heavy SMS and Voice calls users to indulge in to the inappropriate, problematic and excessive use of the mobile phone technology. When the youth do have surplus text messages and voice calls minutes, definitely they use them in the negative ways as mentioned above.

It is interesting to know that the youth perception of inappropriate mobile phone use is limited to class room setting only. Majority of students do not perceive that the mobile phone use is a problem in different public and private settings as documented by the previous researchers such as Bianchi and Phillips, (2005) and Palen, (2008). The real Mobile phone expansion happened in the last four to five years among the Pakistani society. So for majority of the mobile phones users, especially the youth, Mobile phone is relatively a new phenomenon. Youth is unclear about the inappropriate and appropriate uses of this emerging technology. As, it is said that some part of an individual learning comes from the family, but as mentioned above that telephone communication patterns are different among generations, as the mobile phone services were unavailable in most part of Pakistan about 15 years ago. So the youth can not adopt and learn from their parents telephone communication patterns. The main source of learning for the youth in case of mobile phone communications remain the TV advertisements of telecom companies in Pakistan.

The appropriate mobile phone consumption in relation to the place, time and purpose is potentially learnt by youth through the marketing communications of mobile telecom companies in Pakistan. However, this is noticeable that the TV commercials of different telecom companies mostly show students or youth using mobile phones in the different banned settings including class rooms, library and late night etc. Mobile phone communications remain among the emerging values. So, most of these mobile phone communication values are going to be shaped by the marketing communications of telecom operators and not by the other institutions such as family. So the advertising messages and packages are certainly promoting inappropriate use among youth in Pakistan.

Majority of the present study findings suggest similarities of SMS and calling behaviour among youth as mentioned in the previous literature. The study findings have congruity both in terms of positive and negative use of mobile phones among youth. This is due to the fact that the mobile telecom packages (voice minutes and SMS packages) are mostly marketed in same manner in different countries. So, cross cultural similarities in case of mobile phone consumption are expected among the youth segment.

\subsection{Limitation of the study and direction for future research}

This study used a small number of sample and qualitatively explored the calling and texting patterns of youth in Pakistan. So, this study results could serve as a launching pad for the future survey research with a large sample size. Secondly, the present study only addressed the calling and texting behaviour of youth, so another direction for the future research could be to study the consumption patterns of mobile phone hand sets features among youth such as audio, video, camera, internet and music player etc.

\section{Conclusion}

Although, mobile phone communications have benefited the contemporary societies, but the negative aspects of this technology cannot be ignored. Youth mostly indulge themselves intentionally or unintentionally in the inappropriate use of mobile phone. Similarly, telecom operators consciously or unconsciously show TV advertisements and offer packages which encourage misuse of mobile phone voice calls and text messages among youth.

Since, mobile phone use is increasing among Pakistani youth, but no efforts are made to protect the vulnerable high users from the negative consequences, inappropriate and excessive use of mobile phone technology by the telecom companies. Thus, there is a great need to educate the youth about appropriate and inappropriate mobile phone use in relation to the time, place, and purpose of communication.

Telecom regulatory body in Pakistan (Pakistan Telecommunication Authority-PTA) should take an initiative to educate youth about right and wrong use of mobile phone. There could be different ways to educate youth firstly; PTA can start a campaign in education institutions or deliver messages through TV commercials. Second way could be to regulate telecom companies for educating youth about the appropriate mobile phone use. One possible way for the telecom companies to educate youth without incurring significant costs is to send text 
messages about right and wrong use of mobile phone to the subscribers. Another way could be to provide pamphlets and leaflets to users on the time of selling mobile phone sim cards and mobile top up cards etc.

There is a great need of intervention from PTA and to issue a code of advertising for the telecom operators in Pakistan. Telecom companies frequently show inappropriate mobile phone communication practices among youth through TV commercials. Ads showing messages, such as, a student using mobile in class room, in the library, and late night must be barred. As this type of TV ads potentially encourage inappropriate mobile phone use among youth.

\section{References}

Aoki, K., and Downes, E. J. (2003). An analysis of young people's use of and attitudes toward cell phones. Telematics and Informatics, 20, 349-364.

Australian Government. (2005). The social impact of mobile phone use in Australia: a review of data sources Report. Canberra. Department of Communications, Information Technology and the Arts: 1-33.

Bianchi, A., and Phillips, J. (2005). Psychological predictors of problem mobile phone use. Cyber Psychology \& Behaviour, 8, 39-51.

Carroll, J., Howard, S., Peck, J., and Murphy, J. (2002). A Field study of perceptions and use of mobile telephones by 16-22 years olds. Journal of Information Technology Theory and Practice, 4, 49-61.

Chapman, S., and Schofield, W. N. (1998). Lifesavers and cellular Samaritans: emergency use of cellular (mobile) phones in Australia. Sociology of the Mobile Phone Online Publications. [Online] Available: http://socio.ch/mobile/index_mobile.htm, (Sept 14, 2009).

Corti L. (1993). Using diaries in social research, social research update, Issue 2. [Online] Available: http://sru.soc.surrey.ac.uk/SRU2.html (Sept 10, 2009).

Cova, B. (1994). Community and consumption: towards a definition of the 'linking value' of product or services. European Journal of Marketing, 31, 297-316.

Frissen, V. (2000). ICT in the rush hour of life. The Information Society, 16, 65-75.

Griffiths, M., \& Renwick, B. (2003). Misfortune or mismanagement: A study of consumer debt issues. Ourimbah, NSW: Central Coast School of Business, University of Newcastle.

Haste, H. (2005). Joined up texting: mobile phones and young people. Young Consumers, [Online] Available: http: //www.warc.com (Sept 12, 2009).

Haste, H. (2005). joined up texting: mobile phones and young people. Young Consumers, [Online] Available: http://www.warc.com (Sept 19, 2009).

Ito, M. (2006). Mobile Phones, Japanese Youth, and the Re-Placement of Social Contact. [Online] Available: http: //www.itofisher.com/mito/archives/mobileyouth.pdf. (October11, 2009).

James, D., \& Drennan, J. (2005). Exploring Addictive Consumption of Mobile Phone Technology, ANZMAC 2005 Conference: Electronic Marketing, [Online] Available: http://smib.vuw.ac.nz:8081/WWW/ANZMAC2005/cd-site/pdfs/12-Electronic-Marketing/12-James.pdf (November 23, 2009).

Ling, R. (2005). Mobile communications vis-à-vis teen emancipation, peer group integration and deviance. In R. Harper, A. Taylor, \& L. Palen (Eds.), the inside text: Social perspectives on SMS in the mobile age. London: Klewer

Ling, R., \& Yttri, B. (2002). Hyper-coordination via mobile phones in Norway. In J. Katz \& M. Aakhus (Eds.), Perpetual contact: Mobile communication, private talk, public performance (pp.139-169). Cambridge, UK: Cambridge University Press.

Matthews, R. (2004). The Psychosocial aspects of mobile phone use among adolescents. In Psych, 26, 16-19.

McEvoy,S.P., Stevenson, M. R.., McCartt, A.T., Woodward, M. Haworth, C., Palamura, P., and Cercarelli, R. (2005). Role of mobile phones in motor vehicle crashes resulting in hospital attendance: A case-crossover study, British medical Journal. [Online] Available: http//press.psprings.co.uk/bmi/july/mobilephones.pdf (October 12, 2009)

Mehran, A.K. (2009) Telecom Sector shows 20\% Revenue Growth in year 2008-09. [Online] Available: http:/www.pta.gov.pk/index.php?option=com_content\&task=view\&id=1332\&catid=92\&Itemid=301

(November 30, 2009) 
Monk, A., Carroll, J., Parker, S., \& Blythe, M. (2004). Why are mobile phones annoying? Behavior and information technology, 23, 33-41.

Mort, G.S., \& Drennan, J. (2004). Marketing m-services: establishing a usage benefit typology relating to mobile user characteristics. Database Marketing \& Customer Strategy Management, 21 327-341.

Palen, L., Salzman, M., and Young, Ed. (2008). Going Wireless: Behavior \& Practice of New Mobile Phone Users. [Online] Available: http://www.cs.colorado.edu/ palen/Papers/cscwPalen.pdf (November 10, 2009).

Palen, L., Salzman, M., \& Youngs, E. (2001). Discovery and integration of mobile communications in everyday life. Personal and Ubiquitous Computing, 5, 109-122.

Paragas, F. (2003). Being mobile with the mobile: Cellular telephony and renegotiations of public transport as public sphere. Paper presented at the Front Stage/Back Stage: Mobile Communication and the Renegotiation of the Social Sphere Conference, Grimstad, Norway

Power, M. R., and Horstmanshof, L. (2004). YYSSW (Yeah, yeah, sure, sure, whatever): keeping and supporting relationships through SMS text messaging. Human Communication and Technology Communication, National Communication Association Annual Convention, Chicago, Illinois.

Power, M. R., and Power, D. (2004). Everyone here speaks txt: deaf people using SMS in Australia and the rest of the world. Journal of Deaf Studies and Deaf Education, 9, 333- 343.

Qizilbash, R. S. (2007). Documentation and verification of cellular phone customers. [Online] Available: http://www.pta.gov.pk/index.php?option=com_content\&task=view\&id=970\&catid=95\&Itemid=229 (November 30, 2009).

Srivastava, L. (2005). Mobile Phones and Evolution of Social Behaviour, Behaviour and Information Technology, 24, 111-129.

Sultana, M. (2006). A brief on productive health of adolescents and youth in Pakistan, Culture of Silence. [Online] Available: http://www.popcouncil.org/pdfs/Pak_AYP001.pdf (November 30. 2009)

Taylor, A.S. \& Harper, R. (2001). Talking activity: young people and mobile phones. Paper presented at CHI 2001 Workshop: Mobile Communications: Understanding Users, Adoption and Design.

Tjong, S., Weber, I., and Sternberg, J. (2003). Mobile, youth culture, shaping telephone use in Australia and Singapore. ANZCA03 Australian and New Zealand Communication Association: Designing communication for diversity, Brisbane, Queensland.

Warner, J. (2003). Beyond the Net, Cell phones shape social behavior among teens in Japan, First publication,

The Miami Herald, Monday, April. 7, 2003. [Online] Available: http://jcwarner.com/writing/4-07-03-cell-phones.htm (November 23, 2009).

\section{Appendix 1.}

Table 1. Total duration of received and dialed calls by college students on the diary day

\begin{tabular}{|l|c|c|c|c|c|c|c|c|}
\hline & \multicolumn{2}{|c|}{$\begin{array}{c}\text { Received } \\
\text { Calls }\end{array}$} & Total & \multicolumn{2}{c|}{$\begin{array}{c}\text { Dialed } \\
\text { Calls }\end{array}$} & Total & \% of \\
\hline & M & FM & Participants & Participants & M & FM & Participants & Participants \\
\hline None & 5 & 4 & 9 & $11.68 \%$ & 8 & 6 & 14 & $18.18 \%$ \\
\hline $1-15$ Minutes & 16 & 19 & 35 & $45.45 \%$ & 12 & 12 & 24 & $31.16 \%$ \\
\hline $16-30$ Minutes & 8 & 5 & 13 & $16.89 \%$ & 6 & 9 & 15 & $19.48 \%$ \\
\hline $31-45$ Minutes & 6 & 3 & 9 & $11.68 \%$ & 8 & 6 & 14 & $18.19 \%$ \\
\hline 46-60 Minutes & 2 & 2 & 4 & $5.20 \%$ & 3 & 1 & 4 & $5.20 \%$ \\
\hline Above one hour & 5 & 2 & 7 & $9 \%$ & 5 & 1 & 6 & $7.79 \%$ \\
\hline Total & $\mathbf{4 2}$ & $\mathbf{3 5}$ & $\mathbf{7 7}$ & $\mathbf{1 0 0 . 0 0 \%}$ & $\mathbf{4 2}$ & $\mathbf{3 5}$ & $\mathbf{7 7}$ & $\mathbf{1 0 0 . 0 0 \%}$ \\
\hline
\end{tabular}


Table 2. Number of received and dialed calls by a college student on the diary day

\begin{tabular}{|l|c|c|c|c|c|c|c|c|}
\hline & \multicolumn{2}{|l|}{$\begin{array}{l}\text { Received } \\
\text { Calls }\end{array}$} & \multicolumn{2}{l|}{ Total } & \multicolumn{2}{c|}{$\begin{array}{l}\text { Dialed } \\
\text { Calls }\end{array}$} & Total & \% of \\
\hline & M & FM & Participants & Participants & M & FM & Participants & Participants \\
\hline None & 5 & 4 & 9 & $11.68 \%$ & 8 & 6 & 14 & $18.20 \%$ \\
\hline $1-4$ Calls & 23 & 19 & 42 & $54.54 \%$ & 20 & 17 & 37 & $48 \%$ \\
\hline 5-8 Calls & 08 & 07 & 15 & $19.48 \%$ & 7 & 5 & 12 & $15.60 \%$ \\
\hline 9-12 Calls & 2 & 2 & 4 & $5.20 \%$ & 3 & 4 & 7 & $9.10 \%$ \\
\hline $13 \quad \&$ Above & 4 & 3 & 7 & $9.10 \%$ & 4 & 3 & 7 & $9.10 \%$ \\
\hline Total & $\underline{\mathbf{4 2}}$ & $\underline{\mathbf{3 5}}$ & $\underline{\mathbf{7 7}}$ & $\underline{\mathbf{1 0 0 . 0 0} \%}$ & $\underline{\mathbf{4 2}}$ & $\underline{\mathbf{3 5}}$ & $\mathbf{7 7}$ & $\mathbf{1 0 0 . 0 0 \%}$ \\
\hline
\end{tabular}

Table 3. Average SMS and calls received and made by a college student on the dairy day

\begin{tabular}{|l|c|c|}
\hline Average SMS and calls received and made & Male & Female \\
\hline Average Number of a received calls & 4.3 & 4.1 \\
\hline Average Number of a dialed calls & 3.9 & 3.4 \\
\hline Average Number of SMS received & 98.4 & 85.7 \\
\hline Average Number of SMS sent & 109.5 & 98.2 \\
\hline
\end{tabular}

Table 4. Calls and SMS made and received on different times on the diary day

\begin{tabular}{|l|c|c|c|c|}
\hline Time & SMS received & SMS sent & $\begin{array}{l}\text { Calls } \\
\text { received }\end{array}$ & Calls dialed \\
\hline 6:01AM to 12:00 PM & $23.3 \%$ & $20.40 \%$ & $6.20 \%$ & $4.70 \%$ \\
\hline 12:01 PM to 18:00 PM & $21.5 \%$ & $24.20 \%$ & $19.30 \%$ & $17 \%$ \\
\hline 18:01PM to 00:00AM & $48.0 \%$ & $50.80 \%$ & $39.50 \%$ & $45.20 \%$ \\
\hline 00:01 AM to 6:00 AM & $7.2 \%$ & $4.60 \%$ & $35 \%$ & $33.10 \%$ \\
\hline Total & $100.0 \%$ & $100.00 \%$ & $100.00 \%$ & $100.00 \%$ \\
\hline
\end{tabular}

Table 5. Total Average SMS received and sent by a college student on the diary day

\begin{tabular}{|c|c|c|c|c|c|c|c|c|}
\hline \multirow[t]{2}{*}{ No. of SMS } & \multicolumn{2}{|c|}{$\begin{array}{l}\text { Received } \\
\text { SMS } \\
\end{array}$} & \multirow{2}{*}{$\begin{array}{c}\text { Total } \\
\text { Participants }\end{array}$} & \multirow{2}{*}{$\begin{array}{c}\% \text { of } \\
\text { Participants }\end{array}$} & \multicolumn{2}{|c|}{$\begin{array}{l}\text { Sent } \\
\text { SMS }\end{array}$} & \multirow{2}{*}{$\begin{array}{l}\text { Total } \\
\text { Participants }\end{array}$} & \multirow{2}{*}{$\frac{\% \text { of }}{\text { Participants }}$} \\
\hline & $\mathrm{M}$ & FM & & & $\mathrm{M}$ & $\mathrm{FM}$ & & \\
\hline None & 2 & 1 & 3 & $3.90 \%$ & 1 & 1 & 2 & $2.60 \%$ \\
\hline 1-25 SMS & 5 & 4 & 9 & $11.70 \%$ & 4 & 3 & 7 & $9.10 \%$ \\
\hline 26-50SMS & 6 & 5 & 11 & $14.30 \%$ & 4 & 4 & 8 & $10.38 \%$ \\
\hline 51-75 SMS & 7 & 4 & 11 & $14.29 \%$ & 6 & 5 & 11 & $14.28 \%$ \\
\hline 76-100 SMS & 3 & 5 & 8 & $10.37 \%$ & 3 & 4 & 7 & $9.10 \%$ \\
\hline 101\&above & 19 & 16 & 35 & $45.44 \%$ & 24 & 18 & 42 & $54.54 \%$ \\
\hline Total & 42 & $\underline{35}$ & $\underline{77}$ & $100.00 \%$ & $\underline{42}$ & $\underline{35}$ & 77 & $100.00 \%$ \\
\hline
\end{tabular}

Table 6. Mobile Phones monthly expenses by the students

\begin{tabular}{|l|c|c|c|c|}
\hline Monthly phone expenses & & & & \% of \\
\hline Amount In Pakistani Rupees & Male & Female & Participants & Participants \\
\hline Less than 100 & 8 & 6 & 14 & $18.18 \%$ \\
\hline $100-250$ & 10 & 8 & 18 & $23.37 \%$ \\
\hline $251-500$ & 18 & 16 & 34 & $44.16 \%$ \\
\hline $501-750$ & 6 & 5 & 11 & $14.29 \%$ \\
\hline Total Participants & $\mathbf{4 2}$ & $\mathbf{3 5}$ & $\mathbf{7 7}$ & $\mathbf{1 0 0 . 0 0 \%}$ \\
\hline
\end{tabular}

